\title{
THROMBOANGIITIS OBLITERANS
}

\author{
By C. C. Burt, B.Sc., M.B., Ch.B. \\ From the Department of Surgery, University of Edinburgh
}

\section{Introduction}

In a paper published in 1908 Buerger discussed the occurrence in young men of obliterative arterial disease to which the terms endarteritis obliterans, presenile gangrene and juvenile gangrene had previously been applied. In later publications (1917, 1924), he gave an account of its clinical features and treatment in more then 300 cases. Buerger's contention was that the disease manifested itself by episodes of segmental mural inflammation and occlusive thrombosis in mediumsized arteries and veins which later tended to spread proximally to involve larger vessels; ultimately organization and partial recanalization of the thrombus occurred. He suggested the name "obliterating thromboangiitis' for this. After this paper it was generally accepted that Buerger's description applied to a clinical and pathological entity.

However, although there is general agreement that a diagnosis of thromboangiitis obliterans can be made with fair certainty in young patients in the 20's and 30's, except in the presence of pathological proof there has always been some uncertainty as to the diagnosis in the 40 to 50 age group. In recent years, with the more general use of arteriography, it has become possible to determine the exact distribution of arterial lesions. Using this method, Boyd et al. (1949) have attempted to clarify matters from both the aetiological and diagnostic points of view and have suggested that there are four types of arterial thrombosis: (I) traumatic arterial thrombosis, (2) juvenile obliterative arteritis, (3) primary popliteal thrombosis and (4) senile obliterative arteritis. They describe patients suffering from juvenile obliterative arteritis as a group in which the lesions begin in small vessels and may spread proximally. They suggest that this group appears to correspond to that described by Buerger and concede that it may be a pathological entity, but consider that in many other cases of obliterative arterial disease in young adults in whom the lesions begin in the femoral or popliteal arteries, trauma in the adductor canal or behind the knee joint is the aetiological factor. This may be so in some cases, and was suggested as a possible aetiological factor by Learmonth et al. (1944), when they discussed four cases of unilateral arterial thrombosis, three of which were in either the popliteal or femoral artery. The subsequent history of one of these patients is of interest because during the next 14 years he developed at intervals of several years combined distal and proximal arterial blocks in the other leg, recurrent migratory phlebitis, cerebral thrombosis, and in the fourteenth year, following partial gastrectomy, a small splenic infarct and an arterial block in the left forearm.

Mavor (1955) based his diagnosis of thromboangiitis obliterans on the finding of distal arterial blocks shown by arteriography. He also stated that there was doubt whether thromboangiitis obliterans ever affected vessels in the upper limb or visceral vessels. This is not always the case a patient first seen in this Unit at the age of 25 years with an arterial block in one upper limb showed typical signs of distal arterial blocks in the right and left legs three and six years later respectively. In a review of 85 patients, Richards (1953) described clinical evidence of involvement of the arteries in the upper limbs in 25 (29 per cent.), and suggested that in cases which do not conform to the classical picture the clinical diagnosis can be only a tentative one. We feel that years may elapse before it is certain.

Buerger's original concept may have to be modified but at present it still provides a convenient clinical label for purposes of classification and treatment.

\section{Pathology}

Buerger ( $19 \odot 8)$ based his original diagnosis largely on the pathological and histological study of 19 amputated limbs. He considered that the disease usually affected the distal segments of arteries rather than the proximal, but that it might spread proximally or might occur segmentally with normal intervening portions of vessel. He pointed out that if sufficient vessels were examined, the obliterative process could be studied at any stage in its development. In recently blocked 
arteries and veins he found the lumen occluded by red thrombus and the media and adventitia infiltrated by polymorphs and round cells. In slightly older lesions, infiltration with fibroblasts and occasional giant cells (Fig. I) were to be found and these changes were followed by organization, vascularization and frequently a considerable degree of canalization of the thrombus (Fig. 2). These channels extend from side branches of occluded vessels and drain into vasa vasorum or other side channels (Wilson, I950). In some cases where there had been an intense cellular reaction, the media and adventitia of the vessel wall might be almost replaced by fibrous tissue and the artery companion veins and nerve might ultimately be bound together in a fibrous mass. The internal elastic lamina was usually preserved. Buerger pointed out that in older lesions, as a result of canalization and fibrous change, the picture might closely resemble that due to intense proliferation of the intima, a point which Michels and Parkes Weber (I903) had previously made.

\section{Clinical Features}

Buerger recognized and emphasized that the clinical features of thromboangiitis obliterans are mainly due to the thrombotic lesions and that they are similar to those found in cases of vascular occlusion from other causes. In other words, thromboangiitis obliterans shares with a number of other conditions the general symptoms and signs of ischaemia.

Symptoms and Signs of Ischaemia in a Limb.

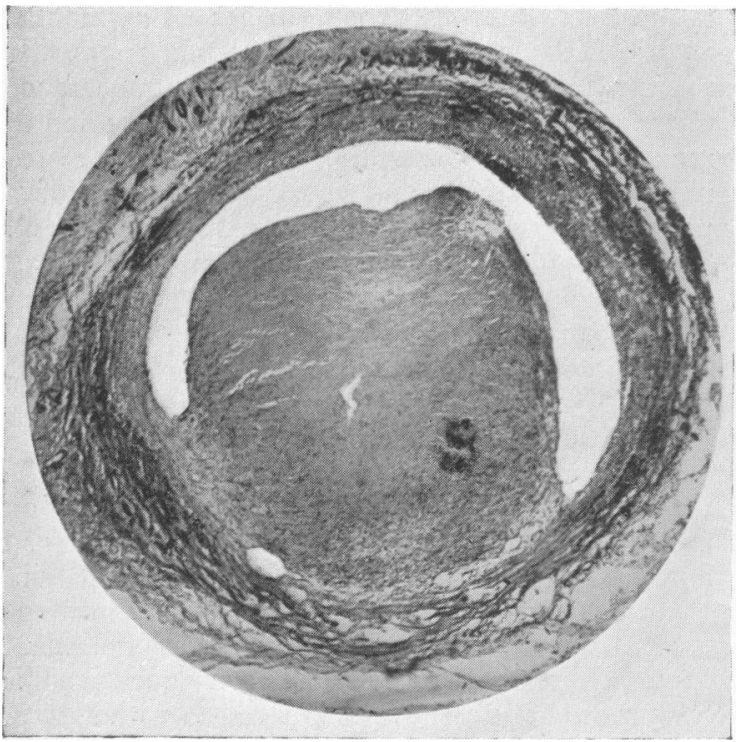

FIG. 1.-Recent thrombus in a vein affected by migratory phlebitis, showing giant cell.
These can be divided into two groups: (I) those induced by exercise and relieved by rest and (2) those unrelated to exercise but possibly modified by posture.

(I) The most important symptom in the first group is that of intermittent claudication, a term now generally regarded as synonymous with muscle pain on exercise. The level of arterial narrowing or block is always at or proximal to the group of muscles in which pain occurs, and in the case of pain in the calf may be anywhere from the bifurcation of the aorta to the popliteal artery (Lindbom, 1950). Undue pallor of the skin with or without a feeling of numbness may also appear on exercise.

(2) Early features unrelated to exercise are pallor at rest or on elevation, and undue coldness of the affected extremity. Later there may be found excessive rubor or cyanosis on dependency, and following long-standing vascular insufficiency there may be wasting and atrophy of distal muscles, atrophy of skin and pulp of digits and irregular and poor growth of nails. If ischaemia is gross there may be severe rest pain in the distal parts of the limb, usually relieved by dependency, occasionally by elevation: this is always a sign of impending gangrene.

Clinical Features which Differentiate Thromboangiitis Obliterans from Other Causes of Arterial Occlusion. The disease occurs almost exclusively in males and the age of onset is usually in the 20 's or early 30's (Fig. 3 ).

It is an episodic disease which may begin insidiously with minor symptoms or may spread

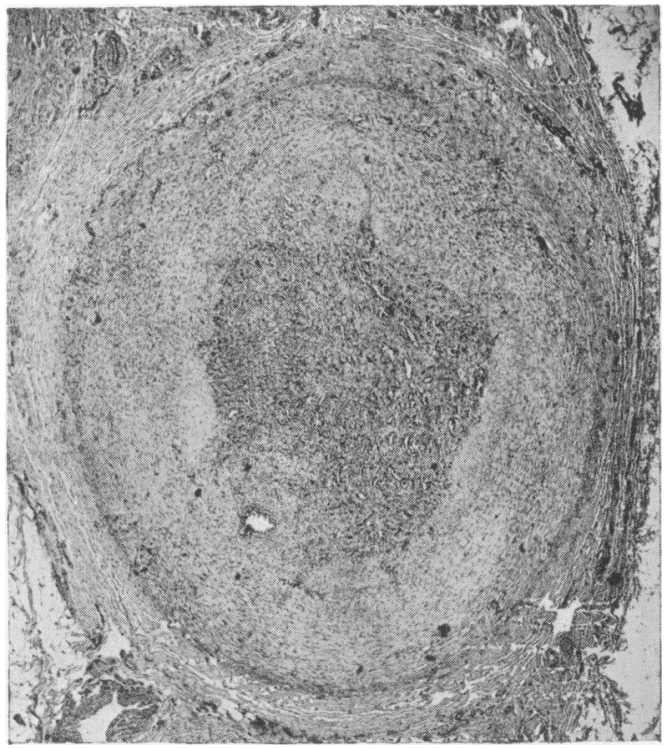

Fig. 2.-Organization and early recanalization in artery. 
AND ARTERIOSCLEROSIS

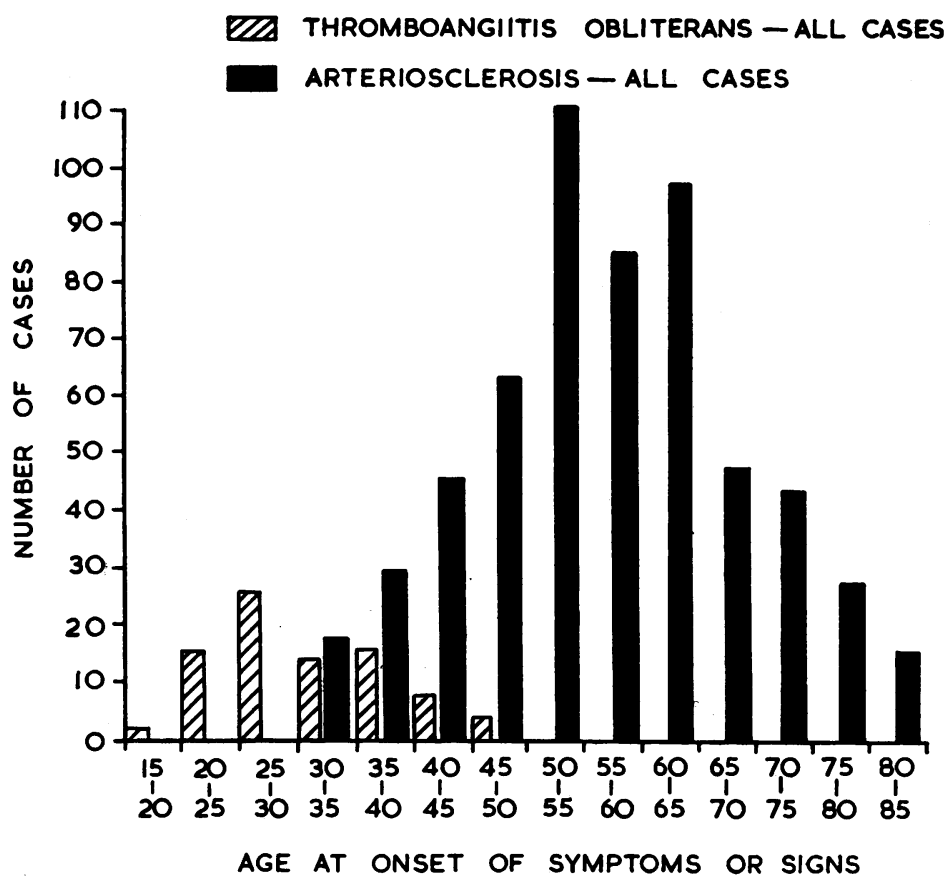

FIG. 3.-Comparison of incidence in age groups between thromboangiitis obliterans and arteriosclerosis obliterans. (Modified from Learmonth, 1952.)

with extreme suddenness to involve almost all the distal vessels in a limb and cause rapidly increasing gangrene. All gradations of intensity and rapidity of spread exist; remissions may occur and may last for years only to be followed by a fulminating bout of thrombosis in a limb perhaps previously unaffected. Buerger pointed out that few patients are seen in the early stages of the disease, when only small segments of distal vessels are involved; at that time symptoms may be minor and consist only of poorly localized pain in a foot. When plantar vessels only are involved, the dorsalis pedis or perforating peroneal and posterior tibial pulses may be present, and in the upper limb if palmar vessels only are affected the radial and ulnar pulses may be palpable. In this early stage many patients do not seek advice, considering that the symptoms in the lower limb are due to 'flat feet' or to 'arthritis'; it is only later when proximal spread of thrombosis has occurred and walking distance is limited by calf pain that they seek a medical opinion. Occasionally a patient will report early with the complaint of pain in a foot precipitated by exercise; this always indicates a block in the plantar vessels or in the distal part of the posterior tibial artery.
Migratory phlebitis occurs in between 25 per cent. and $5^{\circ}$ per cent. of cases of thromboangiitis obliterans (Buerger, r908, 1924; Learmonth, 1952; Richards, 1953; Allen et al., 1955). It may precede, accompany or follow the appearance of the arterial lesion and there may be a period of many years between the first appearance of migratory phlebitis and the disappearance of a peripheral pulse (I8 years, Learmonth, I952). The conjunction of migratory phlebitis and 3 . occlusive arterial disease is almost pathognomic of thromboangiitis obliterans.

Differential diagnosis must be made from other causes of arterial and venous occlusion:

(I) Simple Arterial Thrombosis. The association of the onset of symptoms with a toxic or a febrile illness, with antecedent trauma or the finding of an $\Omega$ anatomical cause for what might be termed $N$ autogenous trauma, for example cervical rib, స్ట should suggest that the lesion is not thromboangiitis. In cases which present as unilateral 0 superficial femoral or popliteal artery occlusions it may not be possible to make a pathological $\stackrel{\leftrightarrow}{?}$ diagnosis with certainty.

(i) Embolic Lesions. Peripheral emboli present with sudden onset of pain, motor and sensory loss 
and it is seldom that initial symptoms are so severe in the case of thromboangiitis obliterans. In cases of embolic arterial occlusion a cardiac or other source for the embolus is usually evident on clinical examination.

(3) Other Types of Arteritis. The finding of a positive Wassermann test or of eosinophilia will exclude thromboangiitis obliterans. In polyarteritis nodosa the lesions are almost always in small vessels and a severe systemic upset with hypertension and albuminuria is also present. Biopsy may be necessary to establish the diagnosis. The history of a systemic upset and the distribution of the lesions make the clinical differentiation of temporal arteritis fairly easy.

(4) Arteriosclerosis Obliterans. This is the most difficult differential diagnosis to make and in some cases it may be impossible to be certain without pathological evidence. After the age of 40 the appearance of occlusive arterial lesions is more likely to be due to arteriosclerosis than to thromboangiitis obliterans. Radiological evidence of arterial calcification and a high blood cholesterol and lipid level are indicative of arteriosclerosis. Nutritional lesions are more common-presenting features in thromboangiitis obliterans than in arteriosclerosis, being found in 48.3 per cent. of the former and in 8.5 per cent. of the latter (Learmonth, 1952). An arteriogram may give additional evidence by demonstrating the typical ' nibbled' appearance of arteriosclerotic vessels. Nevertheless, in many cases it will be impossible to differentiate with certainty between thromboangiitis obliterans and arteriosclerosis obliterans, although it may be quite easy to make an anatomical diagnosis of the affected vessel, level and extent of the block.

(5) Migratory Phlebitis. Rarely the presence of migratory phlebitis may be associated with a previously undisclosed neoplasm (Trousseau, I868) or with chronic dental or other sepsis. However, in such cases the main veins of a limb are also frequently thrombosed. Bland thromboses in varicose veins should not present any difficulty in diagnosis.

\section{Aetiology}

The aetiology of thromboangiitis obliterans is still unknown.

Sex. The disease is almost entirely confined to males. This raises the question of the involvement of a hormonal factor, the female hormone protecting against or the male hormone being necessary for its development. McGrath (1935) obtained experimental evidence of the protective effect of oestrone against experimental gangrene in animals, and also of its beneficial effect in lesions caused by obliterative arterial disease in man.
Haematological Changes. Buerger pointed out that it was unlikely that the disease was due to a thrombotic lesion alone because the pathological lesions differ from those of bland thrombosis, but at times various changes have been reported in the blood, such as haemoconcentration, increased viscosity, increased coagulability (Theis and Freeland, 1939) and increased heparin resistance (de Takats, I 943). In the majority of cases tested, plasma cholesterol, phospho-lipids and lipids have been normal (Roth et al., I 938). In patients with active migratory phlebitis, Ingram (1955) has reported a greater reactivity of factor $\mathrm{V}$.

Trauma and Exposure to Cold. Both tend to increase the severity of symptoms already present, but there is no evidence that either is an aetiological factor.

Infection. Although convinced from the appearance of the lesions that there must be an infective agent, Buerger ( 1929 ) failed to culture any organism from biopsies of acute lesions but claimed to have produced typical lesions in ligatured portions of superficial veins of volunteers by paravascular implantation of clot from acute lesions.

Successful culture of an organism from affected veins was reported by Rabinowitz (1923) and by Horton and Dorsey (1932): the former isolated a Gram-negative bacillus and the latter a Grampositive streptococcus. It was claimed that both organisms when injected into rabbits in some cases caused vascular lesions similar to those of thromboangiitis obliterans in man. These findings were not confirmed by later experiments (Allen et al., I948).

The frequent association of epidermophytosis with thromboangiitis obliterans also attracted notice. Naide (I94I) reported 80 per cent. positive responses to intradermal skin tests with trichophyton in patients suffering from thromboangiitis obliterans, and only 20 per cent. positive in normal subjects. More recently, Boyd et al. (1949) have again emphasized the possible importance of the frequent association of interdigital fungal infection and thromboangiitis obliterans.

Tobacco. The majority of patients who suffer from thromboangiitis obliterans are heavy smokers. In many persons cigarette smoking causes peripheral vasoconstriction (Wright and Moffat, I934; Maddock et al., 1936; Shepherd, 1951), and in subjects with an already impaired circulation superimposed vasoconstriction can be dangerous. Because of this there is an almost unanimous opinion that cigarette smoking is a serious aggravating factor. From clinical experience it is believed that the disease tends to progress more rapidly in the case of patients who continue to smoke and that cessation of smoking is frequently 
followed by remission of symptoms (Silbert, 1935). Allergy. Using intradermal tests, Sulzberger (1934) found some evidence of abnormal sensitivity to a variety of allergens including tobacco in subjects with thromboangiitis obliterans, but this has not been confirmed by later workers (Westcott and Wright, 1938). However, thromboangiitis obliterans may be an allergic response to a variety of substances in subjects who respond to an allergen by thrombosis, possibly because they have unduly sensitive vessels or an easily upset thromboplastin generation or other blood coagulation mechanism. Sensitivity of this type has been suggested to account for the high incidence of fungal infection noted to precede manifestations of thromboangiitis obliterans (Thomson, 194I).

In relation to this it may be of interest to record that in this Unit it was noted that the use of intravenous pentothal in patients suspected of having thromboangiitis obliterans has been almost invariably followed in four to seven days by thrombosis of the vein into which it was injected; it is now a rule that intravenous pentothal should never be given to such patients.

\section{Treatment}

Buerger stated that there was no treatment for the acute stage and wrote: "When we speak of treatment of the disease we are in truth referring to therapies of the consequencies of the healed stage and not of the morbid processes per se.' As the aetiology is still unknown, this is largely true today. However, various measures have been and are used in an endeavour to prevent spread of the disease; otherwise treatment is designed to prevent exposure of the ischaemic limbs to factors which might increase the ischaemia, to increase or maintain as large a blood supply as possible to the affected limbs, and to treat infection, ulceration and gangrene if they have occurred.

\section{Measures Designed to Prevent Spread of the Disease}

Anticoagulant Therapy. Theoretically this should be of great help in preventing spread of this disease and early attempts were made to diminish the viscosity of the blood by the use of Ringer's solution (Meyer, 1916, 1918), or to prevent thrombosis by the use of intravenous sodium citrate (Ginsburg, I917). The use of intravenous hypertonic sodium chloride was advocated by Silbert (1935) and by Samuels (1936). In recent years heparin and the coumarin and indanedione anticoagulants have been used. Allen et al. (1955) suggest that anticoagulant therapy should probably be limited to cases of repeated acute arterial occlusions. However, there are also cases where severe and frequently recurring attacks of migratory phlebitis may endanger the nutrition of a limb, and in such cases the thrombotic lesions may be kept partially under control and morbidity may be diminished by the use of long-term anticoagulant therapy (Burt, 1954, 1955). In migratory phlebitis, butazolidin will abolish pain and the inflammatory reaction in a day or two, but the thrombus is not affected; when butazolidin is used in conjunction with anticoagulants, recent lesions of migratory phlebitis resolve in two or three days and the veins may recanalize completely, but the lesions recur as soon as treatment is stopped (personal observation). The danger of agranulocytosis from the administration of butazolidin prevents consideration of long-term combined therapy of this type, but the fact that the use of anticoagulants alone does not prevent minor spread of the phlebitic lesions suggests that in the veins at least the lesions are not primarily thrombotic.

Non-specific Protein Shock Therapy. Barker (I93I) reported favourable results from the use of intravenous T.A.B. vaccine and it has been used particularly during episodes of migratory phlebitis and acute exacerbations of the disease. The febrile reaction which occurs gives a period of vasodilatation, and theoretically if the disease is an allergic response the treatment may have a desensitizing effect.

\section{Measures Designed to Protect Ischaemic Limbs}

The patient must be carefully instructed con cerning the care of the affected limb and the regulation of his life. He may be told that he has a disease which has caused a block of some of the blood vessels to his limb and that because of this it is important he should not do anything which will make the limb do more work than the available blood supply will permit with safety. A sheet of instructions is essential because many patients find it difficult to remember more than one or two points.

\section{Instructions to Patients}

(I) Smoking. It is important that you should stop smoking because tobacco may act on your arteries in such a way that less blood is carried to the skin of your hands and feet.

(2) Cold. You must always protect your skin from cold because this also may diminish the blood supply to it. In cold weather wear warm, comfortable clothes, lined boots or shoes or use insoles to prevent cold striking through the soles to your feet. Warm your underclothes, gloves, socks and shoes before you put them on and thus prevent any loss of your own body heat. At night warm the bed before you go into it. Flannelette sheets are warmer than cotton or linen.

(3) Heat. Never directly heat your affected 
hand/foot in front of a fire or radiator or with a hot water bottle-this may burn the poorly nourished skin.

(4) Washing. For washing use warm water, never hot or cold water, and dry the skin carefully.

(5) Skin. See that nails and corns are looked after properly by a chiropodist if you cannot do it yourself. Careless nail cutting or too severe corn paring can cause damage to the skin which may have serious consequences in your case. If you notice even slight skin damage such as a blister or graze on the affected limb report to your doctor.

(6) Pain on Exercise. Learn to adjust your life to your shorter walking distance-by going slowly you may be able to walk further. Never hurryit is better to wait for the next tram or bus than to run for one and risk increasing the severity of your trouble.

\section{Measures Designed to Increase the Blood Supply}

Sympathectomy. When lower limbs are affected this offers the most effective method of treatment because lumbar sympathectomy gives a permanent result as well as producing an increased superficial blood flow where it is needed, namely, in the affected limb. However, it must be explained to the patient that this operation is designed to preserve and improve nutrition of the skin and that it is unlikely that it will result in any increase in claudication distance. The operation should not be done in the presence of recent ulceration or recent gangrene.

Vasodilator Drugs. Vasodilator drugs can be used to inhibit vasoconstrictor tone but when given orally they tend to produce their maximum effect in the normal, rather than in the ischaemic limbs.

Lasting improvement in skin blood flow as shown by increased warmth in the limbs and healing of ulcers has been reported following the use of injections of insulin (Mazanek, 1949).

If carried out properly, the postural exercises designed by Buerger at least ensure a thorough flushing through of the vascular tree of the affected limb and thus may improve oxygenation of tissues and diminish stasis and the tendency to promote further thrombosis. There is no doubt that many patients with rest pain find comfort in doing these exercises and their use may limit the amount of oedema in those patients who find rest pain relieved by dependency of the affected limb and who would otherwise keep the affected limb constantly in the dependent position.

\section{Treatment of Infection, Ulceration, Gangrene and Pain}

The patient should be treated by rest in bed: if the lower limbs are affected the head of the bed should be slightly raised for part of the day but not long enough to encourage oedema. Reflex vasodilatation should be induced by the use of electrically heated pads to an unaffected area of the trunk or limbs and analgesics should be given to control pain. Heparin may also be given.

The treatment of all skin lesions should be expectant, since in these young patients an excellent collateral circulation may become established. Any fungal infection must be dealt with, and pockets of pus, if present, opened to allow free drainage. For ulcers, bland dressings such as saline may be used but tight bandaging must be avoided and it is better to expose the lesion or to wrap the limb loosely in a towel.

If pain cannot be controlled or gangrene is spreading, a major amputation may become inevitable.

\section{Prognosis}

The prognosis regarding life is usually considered to be good but analysis of three follow-up reports (Telford and Stopford, 1935; Kinmonth, 1948; Lynn and Burt, I949) shows that out of a total of 245 patients 20 had died between one and I4 years after they were first seen. The cause of death was stated to be cardiac in nine patients, to be due to further thrombotic episodes in peripheral vessels in five patients and to causes unrelated to thromboangiitis obliterans in the remaining six patients. From the same reports, it would appear that approximately one patient out of three suffered loss of a lower limb or, taking into account double amputations, one limb in six was lost.

Lynn and Burt (1949) recorded that out of 93 patients who attended for follow-up examination, 45 (including 23 labourers) were still engaged in their original occupations, 24 were doing lighter work and 24 were unemployed. They also found that only 16 of the 93 had stopped smoking, I 5 of these being still in their original occupation.

During periods of remission it has been found that if the patient observes the precautions advised there may be little sign of progression of the disease for many years. Greatest tissue loss occurs during acute and fulminating arterial and venous thrombotic episodes, and although there is as yet no known treatment which will completely abort such attacks, anticoagulant therapy by diminishing spread of thrombus may help to preserve the mouths of collateral channels and thus improve the outlook for the nutrition of the limb after the acute episode is over. Because of the erratic and scattered manifestations of this disease, it is impossible to give a definite prognosis in the case of individual patients when seen for the first time:

Continued on page 242 
than 5 years' duration and the mortality in the present series was 2 I per cent.

\section{Acknowledgments}

I am grateful to the physicians of the Middlesex Hospital for allowing me to study their cases.

This work formed part of a thesis accepted for the degree of D.M. at the University of Oxford.

\section{BIBLIOGRAPHY}

AL'TSCHULE, M. D. (1953), New Engl. F. Med., 248, 808.

BALLET, G. (1907), Med. mod., 18, 255.

BARTELS, E. D. (1946), Acta med. scand., 124, 185.

BERKMAN, J. M. (1930), Amer. F. med. Sci., 180, $4 \mathrm{r}$ r.

BERKMAN, J. M., WEIR, J. F. and KEPLER, E. J. (1947), Gastroenterology, 9, 357 .

BRUCKNER, W. J., WIES, C. H. and LAVIETES, P. H. (I938), Amer. F. med. Sci., 196, 663.

CARMODY, J. T. B. and VIBBER, F. L. (1952), Ann. intern. Med.,

CHARCOT, J. M. (1890), ' Oeuvres Complètes,' Vol. 3, p. 238 , Lecrosnier and Babé, Paris.

COMBY, J. (1908), Arch. Méd. Enf., 11, 562.

CURRAN, w. (1880), Med. Pr., 29, 210.

DECOURT, J. (1946), Paris méd., 36, 249.

DECOURT, J. and MICHARD, J. (1949), Sem. Hôp. Paris, 25, DECOUUR'

Paris, 66, $\mathrm{J}$, and 608 .

ESCAMILLA, R. F. and LISSER, H. (1942), f. clin. Endocrin., 2, 65 .

FABER, K. (1926), Arch. Verdaukr., 37, 17

FARQUHARSON, R. F. (1941), Illinois med. $7 ., 80,193$

FRASER, R. and SMITH, P. H. (194I), Quart. F. Med., N.S.ro, GREENBLATT, R. B., BARFIELD, W. E. and CLARK, S. L. (1951), F. med. Ass. Ga., 40, 299.

GULL, W. W. (1868), Lancet, ii, I $7 \mathrm{I}$.

GULL, W. W. (1874), Trans. clin. Soc. Lond., 7, 22.
HELWEG-LARSEN, P HOFFMEYER, H., KIELER, J., THAYSEN, E. H., THAYSEN, J. H.'THŸGESEN, P. and WULFF, M. H. (I952), Acta med. scand., Vol. 144: sup. 274. HEMPHILI, R. E. (1944), Lancet, ii, 345.

HUBBLE, D. (1952), Ibid., i, I 123

LANDAU, D. R. I., KNOWLTON, K., ANDERSON, D., BRANDT, M.'B. and KENYON, A. T. (1948), 尹́. clin. Endocrin., 8, 133 .

LASEGUE, C. (1873), Arch. gén. Méd., 6 Série, 21, 385.

McCANCE, R. A. et al. (195 I), M.R.C. Special Rep. Series, No. 275, H.M.S.O., London.

McCULLAGH, E. P. and TUPPER, W. R. (r940), Ann. intern. Med., 14, 81 7 .

MacGREGOR, T. N. (1936), Trans. Edinb. obstet. Soc., 56, 153. MALLINSON, P. (1953), Proc. $R$. Soc. Med., 46, 674.

MITCHELL, S. W. ( 1885 ), 'Lectures on diseases of the nervous system especially in women,' Chapter 15, Henry C. Lea, Philadelphia.

MOELLER, E. (1924), Ann. Méd., 16, 45 I.

MORTON, R. (I694), 'Phthisiologia, or a treatise of consumptions,' p.4, S. Smith and B. Walford, London.

MOLIL'TON, R. (1942), Psychosom. Med., 4, 62.

NEMIAH, J.' C. (1950), Medicine, Baltimore, 29, 225

PARDEE, I. (I94I), Med. Clin. N. Amer., 25, 755.

RAHMAN, L., RICHARDSON, H. B. and RIPLEY, H. S. (1939, Psychosom. Med., I, 335.

RICHÄRDSON, H. B. (1939), Arch. intern. Med., 63, I

ROSE, J. A. (1943), Psychosom. Med., 5, 117.

ROSS, T. A. (1936), 'An enquiry into prognosis in the neuroses,' p. 83, University Press, Cambridge.

RYLE, J. A. (1936), Lancet, ii, 893.

RYLE, J. A. (1939), Proc. $R$. Soc. Med., 32, 735

SANDS, D. E. (1953), Ibid., 46, 674.

SHELDON, J. H. (1937), Lancet, i, 360 .

SHELDON, J. H. (1939), Proc. R. Soc. Med., 32, 738.

STEPHENS, L. (1895), Lancet, i, 31

TURNER, R. H. (1938), ' Unpublished communication to American Association of Physicians at Atlantic City 1938,' Quoted by PARDEE, (I94I).

VAN BALEN, G. F. (1939), Acta. med. scand., ror, 433.

WHYTT, R.' (1768), 'The works of Robert Whytt,' p. 598, 'T

Becket and P. A. De Hondt, Edinburgh. W. M. (1946), Sth. med. ₹., Bgham, Ala., 39, 408 .

WILSON, D. C. and SUTHERLAND, I. (I950), Brit. med. F., ii, 862.

Bibliography continued from page 237-C. C. Burt, B.Sc., M.B., Ch.B.

\section{BIBLIOGRAPHY}

ALLEN, E. V., BARKER, N. W., and HINES, E. A. (I948), 'Peripheral' Vascular Diseases,' W. B. Saunders Company, Philadelphia and London.

ALLEN, E. V., BARKER, N. W., and HINES, E. A. (1955), 'Peripheral Vascular Diseases,' 2nd ed., W. B. Saunders Company, Philadelphia and London.

BARKER, N. W. (1931), F. Amer. med. Ass., 97, 84I.

BOYD, A. M., RATCLIFFE, A. H., JEPSON, R. P., and JAMES, G. W. H.'(1949), Ұ. Bone $\mathscr{f}$ t. Surg., 31B, 325 .

BUERGER, L. (1908), Amer. F. med. Sci., 136, 567.

BUERGER, L. (1917), Ibid., 154, 3 19.

BUERGER, L. (1924), "The Circulatory Disturbances of the Extremities,' W. B. Saunders Company, Philadelphia and London.

BUERGER, L. (1929), Arch. Path., 7, 38 I.

BURT, C. C. (1954), Edinb. med. F., 61, 273.

BURT, C. C. (1955), 'Long-term Out-patient Anticoagulant Therapy.' 'In 'Thrombosis and Embolism,' Benno Schwabe $\&$ Co., Basel.

GINSBURG, N. (1917), Amer. F. med. Sci., 154, 328.

HORTON, B. T., and DORSEY, A. H. E. (1932), Arch. Path. I3, 190 .

INGRAM, G. I. C. (1955), 'Laboratory Studies in Migratory' Phlebitis.' 'In Thrombosis and Embolism,' Benno Schwabe \& Co., Basel.

KINMONTH, J. B. (1948), Lancet, ii, 717.

LEARMONTH, SIR JAMES (1952), "The Clinical Study' of Patients with Chronic Obliterative Arterial Disease.' In the Proceedings of the First Congress of the European Society of Cardiovascular Surgery, Strasbourg.

LEARMONTH, J. R., BLACKWOOD, W., and RICHARDS, R. L. (1944), Edinb. med. F., 51, I.

LINDBOM, A. (1950), Acta radiol., Suppl. 80.

LYNN, R. B., and BURT, C. C. (I949), Edinb. med. F., 56, 422.
McGRATH, E. J. G. (1935), Arch. intern. Med., 55, 942.

MADDOCK, W. G., MALCOLM, R. L., and COLLIER, F. A. (1936), Amer. Heart f., 12, 46.

MAVOR, G. E. (1955), Quart. F. Med., 24, 229.

MAZANEK, J. (1949), Brit. med. F., ii, 935.

MEYER, W. (1916), Ann. Surg., 63, 280.

MEYER, W. (I918), Э. Amer. med. Ass., 71, 268.

MICHELS, E., and PARKES WEBER, F. (1903), Brit. med. Ұ., ii, 566.

NAIDE, M. (1941), Amer. F. med. Sci., 202, 822.

RABINOWITZ, H. M. (1923), Surg. Gynec. Obstet., 37, 353.

RICHARDS, R. L. (1953), Brit. med. F., i, 478.

ROTH, G. M., MACLAY, E. V,. and ALLEN, E. J. (1938), Arch. intern. Med., 62, $4 \mathrm{I} 3$.

SAMUELS, S. S. (1936), 'Diagnusis and Treatment of Diseases of Peripheral Arteries,' p. 260, New York University Press.

SHEPHERD, J. T. (195 I), Brit. med. F., ii, 1007.

SILBERT, S. (1935), Surg. Gynec. Obstet., 61, 214.

SULZBERGER, M. B. (1934), F. Amer. med. Ass., ro2, I I.

DE TAKATS, G. (1943), Surg. Gynec. Obstet., 77, 31 .

TELFORD, E. D., and STOPFORD, J. S. (1935), Brit. med. F., i, 863 .

'THEIS, F. V., and FREELAND, M. R. (1939), Arch. Surg., 38. ז9 I. THOMSON, K. W. (r 94 I), New int. Clin., 4, 2 , 156.

TROUSSEAU, A. (I 868), 'Lectures on Clinical Medicine' delivered at the Hôtel Dieu de Paris, Trans. I868, New Sydenham Society, London.

WESTCOTT, F. H., and WRIGHT, I. S. (1938), f. Allergy, 9, 555. WILSON, G. M. (1950), M.D. Thesis, Edinburgh University, Vol. I, p. 77.

WRIGHT, I. S., an 1 MOFFAT, D. (1934), f. Amer. med. Ass., I03 318. 